\title{
Increased Expression of Neuronal Nitric Oxide Synthase (NOS) in Visceral Neurons after Nerve Injury
}

\author{
Margaret A. Vizzard, Susan L. Erdman, and William C. de Groat \\ University of Pittsburgh, School of Medicine, Department of Pharmacology, Pittsburgh, Pennsylvania 15261
}

The distribution of nitric oxide synthase immunoreactivity (NOS-IR) and the changes in this distribution after peripheral axotomy were examined in lumbosacral afferent and preganglionic neurons (PGNs) innervating the pelvic viscera of the male rat. The visceral neurons in L6-S1 and L1L2 dorsal root ganglia (DRG) and in the spinal cord were identified by retrograde axonal transport following injection of Fluorogold (FG) into the major pelvic ganglion (MPG). Axotomy was performed by removing the MPG on one side 2-4 weeks prior to sacrificing the animals. A differential distribution of NOS-IR was detected in DRG cells at different segmental levels of control animals. Significantly greater numbers of NOS-IR cells were present in thoracic (T8, T10, T12; 30-44 cell profiles/section) and rostral lumbar DRGs (L1-L2; 3-15 NOS-IR cell profiles/section) compared to caudal lumbosacral (L5-S1) DRGs (0.2-0.7 cell profiles/section). A significant increase in the number of NOS-IR cells was detected In the L6-S1 DRG $(p \leq 0.001$; 11 NOS-IR cell profiles/section) but not in the L2 or L5 DRG ipsilateral to axotomy. In these ganglia, an average of $\mathbf{3 7 . 0}$ $\pm 4.0 \%$ (L6) and $20.6 \pm 2.2 \%$ (S1), respectively, of FG-labeled pelvic afferent neurons were NOS-IR compared to 1.1 $\pm 0.5 \%$ (L6) and $2.5 \pm 1.4 \%$ (S1) contralateral to the axotomy. Following axotomy, a significantly greater percentage of dye-labeled pelvic visceral afferents in the L1 and L2 DRG also exhibited NOS-IR in comparison to the contralateral side. Following axotomy, NOS-IR fibers were detected along the lateral edge of the dorsal horn extending from Lissauer's tract to the region of the sacral parasympathetic nucleus (SPN) on the ipsilateral side of the L6 and S1 spinal segments. These NOS-IR fibers were not detected in adjacent spinal segments (L4, L5, or S2). Axotomy also changed the numbers of NADPH-d-positive and NOSIR cells in the region of the SPN in the L6 spinal segment. Contralateral to the axotomy $38.3 \pm 4.0 \%$ of PGNs in the L6 spinal segment were colabeled with NOS-IR; however, ipsilateral to axotomy, a significantly greater percentage $(61.0 \pm 3.0 \% ; p \leq 0.01)$ of PGNs exhibited NOS-IR. Axotomy did not alter the distribution of PGNs in the S1 segment exhibiting NOS-IR. These results indicate that NOS-

Received Oct. 11, 1994; accepted Dec. 15, 1994.

This study was supported by NIH Grants DK 37241 and DK 49430 to W.C.G. and by NRSA 1 F32 DK 08916-02 to M.A.V. We thank Ulrich Förstermann. Johannes Gutenberg University, Department of Pharmacology. Mainz, Germany for his generous gift of neuronal NOS antisera.

Correspondence should be addressed to M. A. Viz/ard, University of Pittsburgh. School of Medicine, Department of Pharmacology, W1302, Biomedical Science Tower, Pittsburgh, PA 15261

Copyright 1995 Society for Neuroscience $0270-6474 / 95 / 154033-13 \$ 05.00 / 0$
IR in visceral afferent and PGNs is plastic and can be upregulated by peripheral nerve injury.

[Key words: visceral afferent neurons, preganglionic neurons, lateral collateral pathway, NADPH-diaphorase, nitric oxide synthase, sacral parasympathetic nucleus, intermediolateral cell column, axotomy, dorsal root ganglia]

Nitric oxide (NO) has been implicated as a neurotransmitter or neuromodulator at various sites in the mammalian nervous system (Scherer-Singler et al., 1983; Bredt et al., 1990; Pitkanen and Amaral, 1991; Anderson, 1992; Blottner and Baumgarten, 1992; Schmidt et al., 1992; Valtschanoff et al., 1992b). Neurons containing NO have been identified histochemically by the presence of nicotinamide adenine dinucleotide phosphate diaphorase (NADPH-d) activity or immunocytochemically with an antibody for NO synthase (NOS), the enzyme responsible for NO synthesis (Bredt et al., 1991; Dawson et al., 1991; Vincent and Kimura, 1992).

Previous histochemical and pharmacological studies raised the possibility that $\mathrm{NO}$ is a transmitter in autonomic reflex pathways. In the rat, NADPH-d activity and NOS immunoreactivity are present in sympathetic (Anderson, 1992; Valtschanoff et al., 1992a) and parasympathetic preganglionic neurons in the spinal cord (Saito et al., 1992, 1994; Vizzard et al., 1993c) and in some parasympathetic postganglionic neurons in peripheral ganglia (Burnett et al., 1992; Dail et al., 1992; Keast, 1992; McNeill et al., 1992a,b; Santer and Symons, 1993; Vizzard et al., 1993b, 1994b). NADPH-d activity is also present in a large percentage of visceral afferent neurons in dorsal root ganglia at various levels of the spinal cord of the rat (Aimi et al., 1991; McNeill et al., 1992b; Papka and McNeill, 1992; Vizzard et al., 1993b,c, 1994b). At the lumbosacral spinal level in the rat NADPH-d activity has been identified in bladder, penile, urethral, and pelvic afferent ncurons (McNcill ct al., 1992a,b; Vizzard et al., 1993b,c, 1994b) as well as in a prominent afferent bundle (lateral collateral pathway, LCP) projecting from Lissauer's tract to the region of the parasympathetic nucleus (Vizzard et al., 1993a,c). Prominent NADPH-d-positive afferent fibers are also present in Lissauer's tract and the LCP in S1-S3 spinal segments of the cat (Vizzard et al., 1994a). This afferent pathway closely resembles the central projections of afferent neurons innervating the pelvic viscera (Morgan et al., 1981; Nadelhaft and Booth, 1984; Steers et al., 1991).

Although L6-S1 visceral afferent neurons exhibit NADPH-d activity, NOS-IR was not detected in these neurons or in the LCP of the rat (Vizzard et al., 1994b), cat (Vizzard et al., 1994c), or dog (Vizzard et al., unpublished observations). These data raise the possibility that in L6-S1 visceral afferent neurons NOS is not synthesized and that NADPH-d is not a marker for NOS. 


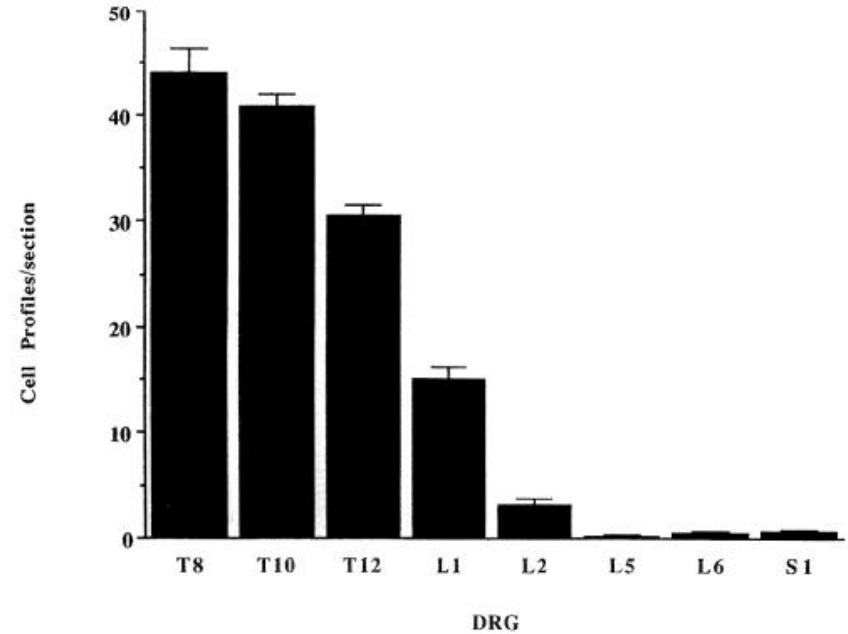

Figure 1: NOS-IR in DRG

Figure 1. Nitric oxide synthase immunoreactivity (NOS-IR) in dorsal root ganglion (DRG) cells at various segmental levels: histogram showing the numbers of NOS-IR DRG cell profiles/section in thoracic (T8, $T 10, T 12)$, rostral lumbar $(L I, L 2)$, and caudal lumbosacral $(L 5-S I)$ DRG.
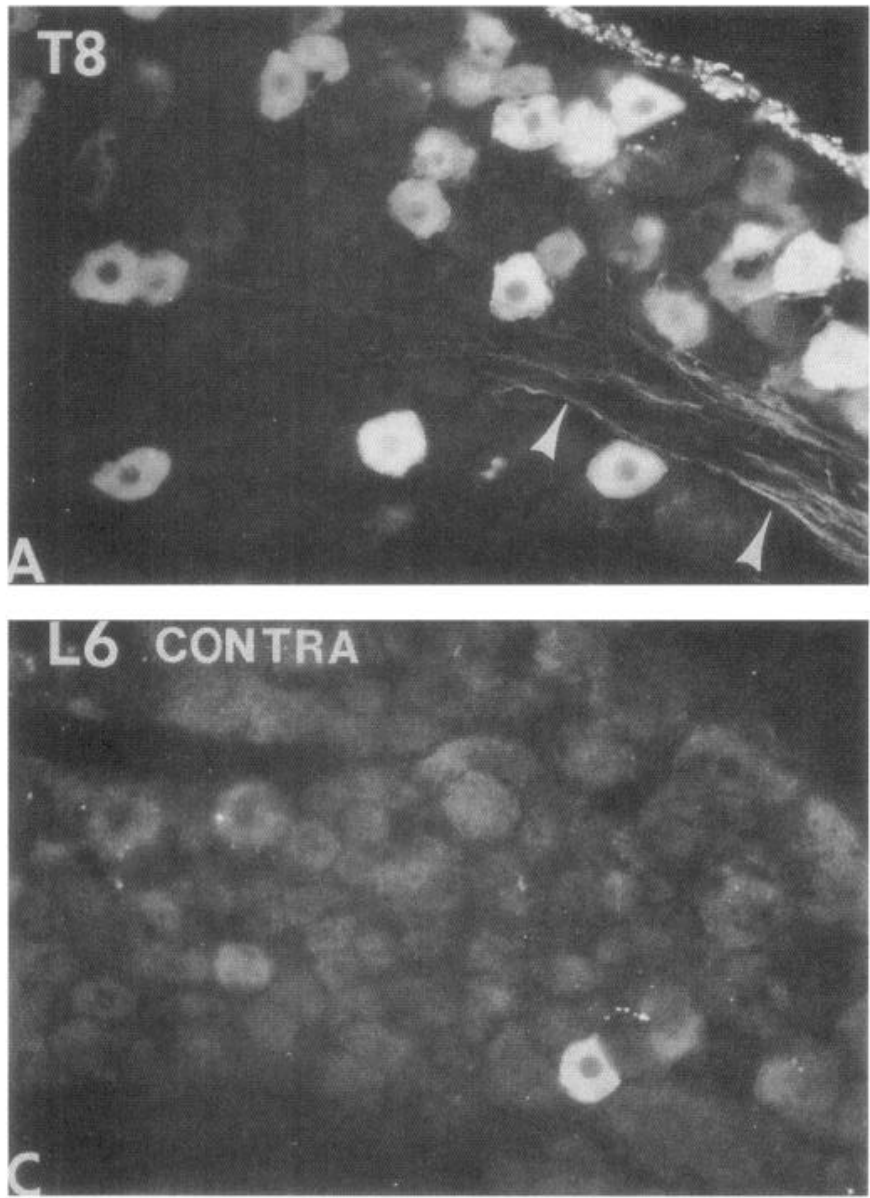

A similar situation exists for somatic afferent neurons in the adjacent L4-L5 DRG, which contain relatively few NOS-IR neurons (Verge et al., 1992; Zhang et al., 1993). However, following sciatic nerve injury the levels of NOS protein and NOS mRNA are markedly increased (Verge et al., 1992; Zhang et al., 1993). Increased NADPH-d staining or NOS-IR has also been noted following axotomy in motoneurons (Gonzalez et al., 1987; Wu, 1992, 1993; Wu et al., 1994) and in some PGNs (Vizzard et al., 1993a) but not in other neurons (Vizzard et al., 1994a; Zhang et al., 1993).

The present study was undertaken to examine the effect of axotomy on NOS expression in visceral neurons. Results indicate that NOS-IR in visceral afferent and efferent neurons is upregulated by peripheral axotomy, suggesting that NOS gene expression is plastic and that neurons that do not normally synthesize NOS can synthesize the protein after interruption of axonal connections with the peripheral target organs.

A preliminary report of these results has appeared in an abstract (Tang et al., 1994).

\section{Materials and Methods}

In rats, the pelvic postganglionic innervation to the bladder, colon, and reproductive organs originates primarily in one large ganglion, the major pelvic ganglion (MPG) (Keast and de Groat, 1989; de Groat and Booth, 1993). Preganglionic efferent axons terminate in the MPG and afferent axons to the pelvic viscera pass through the MPG. Male Wistar
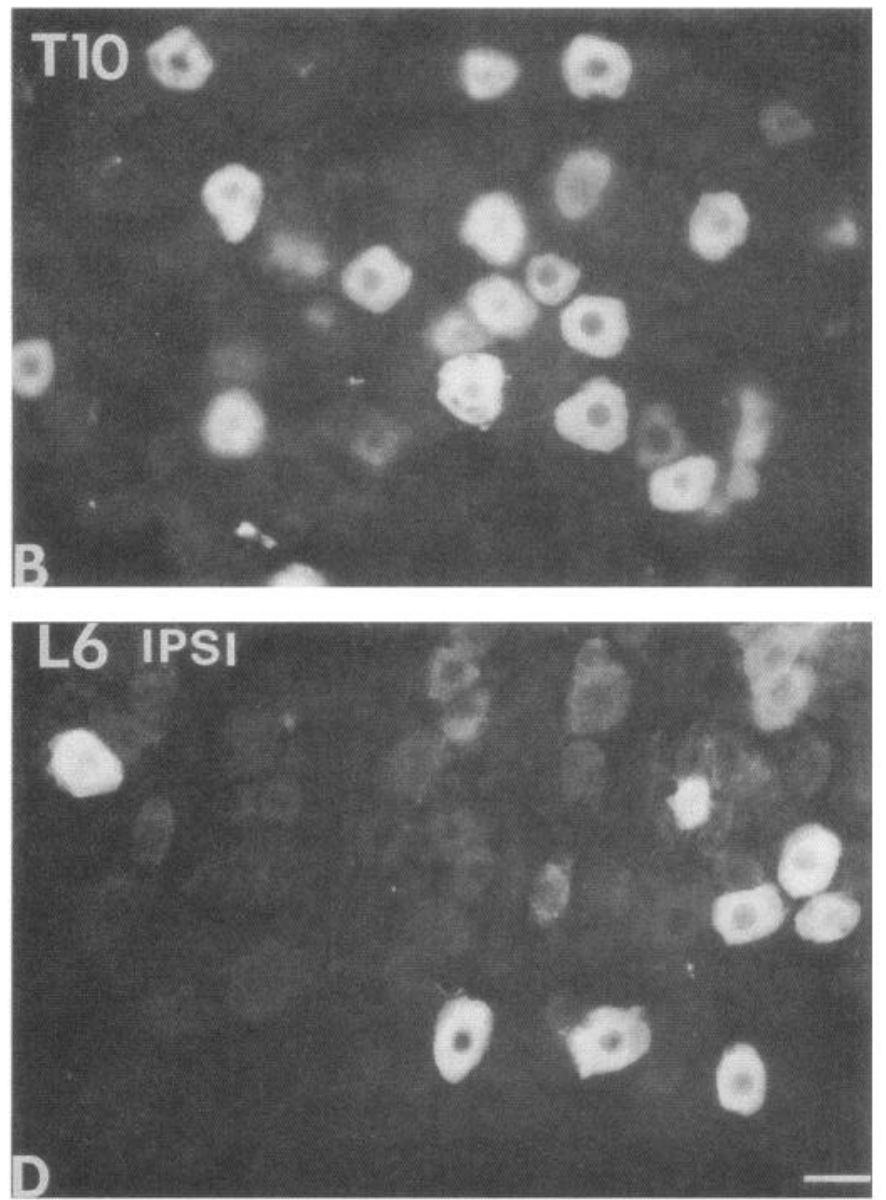

Figure 2. Photomicrographs of NOS-IR afferents neurons in thoracic $(T 8, T 10)$ and lumbar (L6) dorsal root ganglia (DRG). Numerous NOS-IR DRG cell profiles are present in the T8 $(A)$ and T10 (DRG) $(B)$. Bundles of NOS-IR-stained axons $(A$, arrowheads) are also present. Very few NOS-IR cells $(<1$ cell profile/section) are present in the L6 DRG contralateral $(C$, contra) to axotomy as well as in control animals; however, numerous NOS-IR cells (20-fold increase) are present in the L6 DRG ipsilateral ( $D$, ipsi) to axotomy. Scale bar, $25 \mu \mathrm{m}$ for $A-D$. 

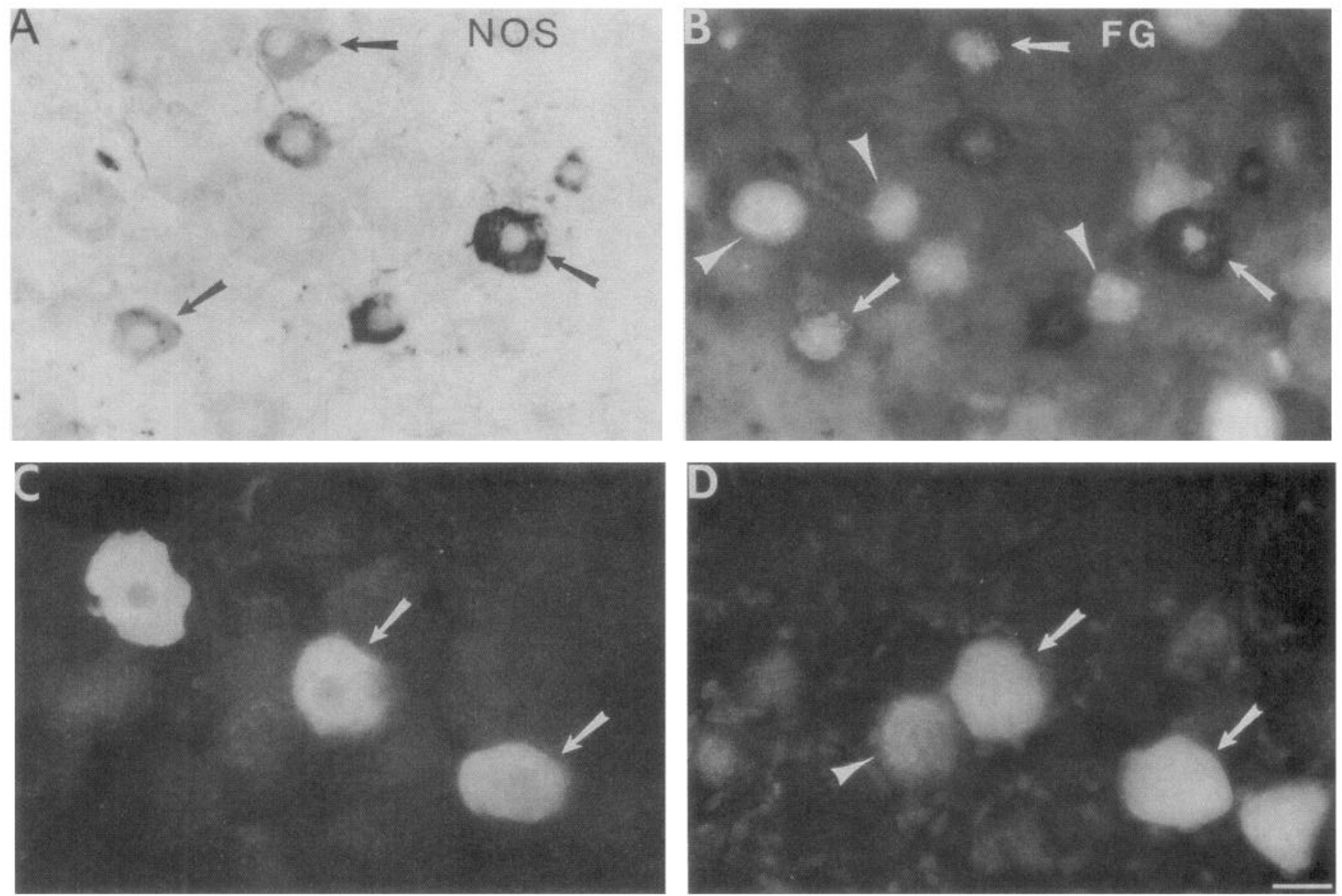

Figure 3. Photomicrographs of Fluorogold (FG)-labeled NOS-IR pelvic visceral afferent neurons in the L6 dorsal root ganglia (DRG) ipsilateral to axotomy. $A$ and $B$, Bright-field $(A)$ and fluorescence $(B)$ photomicrographs of the same DRG section $(28 \mu \mathrm{m})$ showing NOS-IR $(A)$ and FGlabeled pelvic visceral afferent neurons $(B)$. In $A$, NOS staining was visualized using diaminobenzidine $\mathrm{HCl}$ and nickel intensification. This type of staining often obscured the dye such that FG was only obvious in the nucleus and in small cytoplasmic granules. Pelvic visceral afferent neurons (white arrows) that are NOS-IR (black arrows) are indicated. $C$ and $D$, Fluorescence photomicrographs of the same DRG section ( $28 \mu \mathrm{m})$ showing NOS-IR $(C)$ and FG-labeled pelvic visceral afferent neurons $(D)$. In $C$, NOS staining was visualized with an immunofluorescence technique. Pelvic visceral afferent neurons that are NOS-IR are indicated (white arrows). In $B$ and $D$, some pelvic visceral afferents that are not colabeled with NOS are indicated by white arrowheads. Scale bar, $30 \mu \mathrm{m}$ for $A-D$.

\section{Table 1. Numbers of nitric oxide synthase-immunoreactive (NOS-IR) dorsal root ganglion (DRG) cell profiles/section at rostral lumbar (L1-L2) and caudal lumbosacral (L5-S1) levels ipsilateral and contralateral to peripheral axotomy}

Cell profiles/section

\begin{tabular}{lcc} 
& \multicolumn{2}{c}{ Cell profiles/section } \\
\cline { 2 - 3 } DRG & Ipsilateral & Contralateral \\
\hline L1 & $18.7 \pm 1.8^{*}$ & $14.9 \pm 1.2$ \\
L2 & $3.9 \pm 0.9$ & $3.2 \pm 0.6$ \\
L5 & $0.6 \pm 0.3$ & $0.2 \pm 0.1$ \\
L6 & $10.6 \pm 1.1^{*}$ & $0.5 \pm 0.1$ \\
S1 & $10.5 \pm 2.0^{*}$ & $0.7 \pm 0.1$
\end{tabular}

Normally, very few NOS-IR cell profiles are present in the caudal lumbosacral (L5-S1) DRG; however, many NOS-IR cell profiles are present in rostral lumbar levels (L1). Following axotomy, there is a significant increase in the number of NOS-IR cell profiles in the L6-SI DRG $(p \leq 0.001)$ ipsilateral to axotomy as well as a significant increase in NOS-IR cell profiles in the LI DRG $(p \leq 0.05)$ ipsilateral to axotomy. In contrast, no significant increase was detected in the L2 or L5 DRG after axotomy. Numbers of NOS-IR cell profiles in L1-L2 and L5-S1 contralateral to axotomy are not significantly different from the numbers of NOS-IR cell profiles in control animals. rats $(n=14,200-250 \mathrm{gm})$ were anesthetized (halothane, $2 \%)$ and the MPG on one side was surgically removed through a midline abdominal incision to interrupt axons of the pelvic visceral afferent cells in the lumbosacral dorsal root ganglia (DRG) and the preganglionic neurons in the spinal cord. The incision was closed and the animals allowed to recover. In five of these animals 1 week prior to MPG removal, Fluorogold (FG; I $\mu \mathrm{l}, 4 \%$, w/v; Fluorochrome Inc., Englewood, $\mathrm{CA}$ ) was injected into the MPG on both sides to retrogradely label preganglionic neurons in the lumbosacral spinal segments and pelvic afferent neurons in the DRG. After axonal transport of dye, the MPG was removed on one side. Two to four weeks following MPG removal, the animals were deeply anesthetized with pentobarbital (50-60 mg/kg, i.p.) and then sacrificed via intracardiac perfusion first with oxygenated Krebs buffer $\left(95 \% \mathrm{O}_{2}, 5 \% \mathrm{CO}_{2}\right)$ followed by $4 \%$ paraformaldehyde. After perfusion, the spinal cords were quickly removed and postfixed for 2-6 hr. Tissue was then rinsed in phosphate-buffered saline $(0.1 \mathrm{M} \mathrm{NaCl}$, in phosphate buffer, $\mathrm{pH} 7.4)$ and placed in ascending concentrations of sucrose (10$30 \%$ ) in $0.1 \mathrm{M}$ phosphate-buffered saline for cryoprotection. DRG (T8, T10, T12, L1, L2, L5-S1) were sectioned at a thickness of $28 \mu \mathrm{m}$ and the spinal cord (L1, L2, L5-S1) was sectioned in the transverse or sagittal (L5-S1) plane at a thickness of $42 \mu \mathrm{m}$ on a freezing microtome. Tissue from control animals $(n=4)$ (i.e., no axotomy or FG injection into the MPG) was processed in an identical manner as above. 
Table 2. Pelvic visceral afferent neurons exhibiting NOS-IR

\begin{tabular}{llcccccc} 
& \multicolumn{2}{c}{ Cell profiles/section } & & \multicolumn{2}{c}{ Colabel $(\%)$} \\
\cline { 3 - 4 } DRG & \multicolumn{2}{c}{ FG } & NOS-IR & & FG with NOS & NOS with FG \\
\hline L1 & Ipsi & $9.9 \pm 2.9$ & $19.4 \pm 1.5^{*}$ & & $29.6 \pm 1.0^{*}$ & $25.8 \pm 8.9^{*}$ \\
& Contra & $10.3 \pm 2.1$ & $13.2 \pm 1.0$ & & $9.6 \pm 4.3$ & $9.2 \pm 3.5$ \\
L2 & Ipsi & $3.0 \pm 0.5$ & $3.4 \pm 0.7$ & & $28.4 \pm 3.9^{*}$ & $18.2 \pm 5.0^{*}$ \\
& Contra & $2.8 \pm 0.5$ & $2.8 \pm 0.6$ & & $6.0 \pm 2.3$ & $7.6 \pm 2.5$ \\
L6 & Ipsi & $34.1 \pm 2.2$ & $12.1 \pm 1.7^{*}$ & & $37.0 \pm 4.0^{*}$ & $90.9 \pm 5.0^{*}$ \\
& Contra & $38.6 \pm 3.2$ & $0.5 \pm 0.3$ & & $1.1 \pm 0.5$ & $6.6 \pm 6.6$ \\
S1 & Ipsi & $22.8 \pm 1.0$ & $8.1 \pm 1.3^{*}$ & & $20.6 \pm 2.2^{*}$ & $93.0 \pm 4.2^{*}$ \\
& Contra & $26.9 \pm 2.8$ & $0.6 \pm 0.3$ & & $2.5 \pm 1.4$ & $8.7 \pm 6.4$
\end{tabular}

To determine the percentage of pelvic visceral afferent neurons exhibiting NOS-IR, Fluorogold (FG) was injected into both major pelvic ganglia (MPG) 1 week prior to the removal of the MPG on one side. The numbers of FGlabeled and NOS-IR cell profiles/section in the L1, L2, L6, and S1 DRG and the percentage of visceral afferent neurons colabeled with NOS-IR (FG with NOS) ipsilateral and contralateral to axotomy are indicated. Following axotomy, the percentage of dye labeled visceral afferent neurons exhibiting NOS IR at each DRG level (LI, L2, L6, S1) significantly increased $(p \leq 0.01$ ) ipsilateral to axotomy, as did the percentage of NOS-IR neurons with FG labeling (NOS with FG).

Neuronal nitric oxide synthase (NOS) immunohistochemistry. DRG and spinal cord sections were processed, respectively, on slides or using a free-floating method. The tissue was first incubated with potassium phosphate-buffered saline (KPBS) plus $0.4 \%$ Triton X-100 for $60 \mathrm{~min}$ and then incubated for $24-48 \mathrm{hr}$ at $4^{\circ} \mathrm{C}$ with a rabbit polyclonal antibody (1:4500; \#6761-9, Abbott Laboratories, Abbott Park, IL) to rat cerebellar NOS. The rabbit polyclonal antibody to rat cerehellar NOS is specific for NOS isoform I from the brain and does not cross-react with NOS isoforms II or III from induced macrophages or endothelial cells, respectively (Schmidt et al., 1992). After thorough washing, sections were exposed to biotinylated anti-rabbit IgG followed by streptavidinhorseradish peroxidase $(1: 300)$. Staining was visualized with $0.05 \%$ 3',3'-diaminobenzidine $\mathrm{HCl}$ will nickel intensification (nickel annmunium sulfate) in acetate buffer ( $\mathrm{pH} \mathrm{6.0)}$ plus urea $\mathrm{H}_{2} \mathrm{O}_{2}$. Sections were rinsed in KPBS ( $\mathrm{pH} 7.4$ ), air-dried overnight, and coverslipped with Entellan. In one-half of the experiments $(n=7)$ NOS was also detected using an immunofluorescence technique. Sections were incubated on slides for $2448 \mathrm{hr}$ in a humidified box at $4^{\circ} \mathrm{C}$ with NOS antisera (1: 4500). After several rinses with KPBS for $30 \mathrm{~min}$, tissue was incubated with Cy 3-conjugated anti-rabbit IgG (1:600) (Jackson ImmunoResearch Laboratories, West Grove, PA). Sections were again washed in KPBS for $30 \mathrm{~min}$ before coverslipping with a 1:3 mixture of phosphate-buffered saline and glycerin. These sections were viewed using a Leitz fluorescence microscope with a Ploempak N2 filter. Omitting the NOS antibody eliminated NOS immunoreactivity (-IR).

NADPH diaphorase (NADPH-d) histochemistry. Alternate sections of spinal cord (L1, L2, L5-S1) were processed on slides for NADPH-d activity according to the procedure of Vincent and Kimura (1992). Sections were incubated in $0.1 \mathrm{M}$ phosphate buffer ( $\mathrm{pH} 7.4$ ) containing $0.3 \%$ Triton $\mathrm{X}-100,0.1 \mathrm{mg} / \mathrm{ml}$ nitroblue tetrazolium (NBT; Sigma Chemical Co., St. Louis, MO), and $1.0 \mathrm{mg} / \mathrm{ml} \beta-N A D P H$ (Sigma Chemical Co., St. Louis, MO) at $37^{\circ} \mathrm{C}$ for $30-45 \mathrm{~min}$. Following the reaction, the sections were rinsed in phosphate buffer $(\mathrm{pH} 7.4)$, air-dried overnight, and coverslipped with glycerin in phosphate buffer. Omitting either NADPH or NRT in the incubation solution completely blocked all neuronal and fiber staining.

Quantification. NOS-IR cells were counted in 10-25 serial sections of each DRG (L1, L2, L5 S1) ipsilateral and contralateral to the peripheral axotomy. For spinal cord levels T8, T10, and T12 only NOSIR neurons in the contralateral DRG (i.e., opposite to axotomy) were counled since these ganglia do not send axons to the MPG (de Groat and Booth, 1993). Only cell profiles with a nucleus were analyzed. Dorsal root ganglion and spinal cord sections with dye-labeled cells were viewed under a Leitz fluorescence microscope with a Ploempak N2 filter (340-380 nm excitation wavelength for visualizing FG). Cells colabeled with dye and NOS were similarly counted. NOS staining using diaminobenzidine $\mathrm{HCl}$ and nickel intensification often obscured the tracer dye fluorescence in the cytoplasm such that dye fluorescence was only evident in the nucleus and in small cytoplasmic granules in NOS-IR cells (Vizzard et al., 1993c, 1994b). Visualizing NOS-IR with an immunofluorescence technique eliminated this technical difficulty. Increased numbers of NOS-IR in DRG cells were not significantly different 2,3 , or 4 weeks after axotomy. Thus, the data from all survival periuls wele lieated as a single group. NADPH-d activity in DRG was not quantified after axotomy due to the large numbers of these cells and the variations in staining intensity (i.e., intense, moderate, light) (Vizzard et al., 1993a-c, 1994a), which would make it difficult to detect changes in staining. Counts of all NADPH-d-positive and NOS-IR cells in the region of the sacral parasympathetic nucleus (SPN, lateral laminae V-VII) in L6-SI were made in 12-15 consecutive spinal cord sections from each segment in each animal. Cell counts are presented as average number of cell profiles per section (mean \pm SEM). The results are not corrected for double counting. Comparisons between the numbers of NOS-IR cells in the DRG and numbers of NOS-IR/NADPH-d cells in the SPN ipsilateral or contralateral to the peripheral axotomy were made using Student's $t$ test for paired data. Comparisons between numbers of NOS-IR DRG cells or NADPH-d/NOS-IR cells in the region of the SPN in control versus experimental groups were made with analysis of variance. Differences were considered significant if $P \leq$ 0.05 .

\section{Results}

Transection of the preganglionic and visceral afferent axons was performed by removal of the MPG, which is the principal source of the parasympathetic postganglionic innervation as well as a significant contributor to the sympathetic innervation to the bladder, colon, and reproductive organs (for review see, de Groat and Booth, 1993). Thus, MPG removal transected L6-S1 parasympathetic and L1-L2 sympathetic preganglionic axons as well as visceral afferent axons from the rostral lumbar and caudal

Figure 4. Distribution of NOS-IR in the L6 spinal cord following axotomy on the left side. $A$ and $B$, Photomicrographs of the axotomized ( $A$ ) and normal side $(B)$ of the dorsolateral quadrant of the spinal cord. NOS-IR is present bilaterally in cells and fibers in the superficial dorsal horn and in the region of the sacral parasympathetic nucleus $(S P N)$. Greater numbers of NOS-IR cells in the region of the SPN are present ipsilateral to axotomy. $C$ and $D$. Higher-power photomicrographs of the SPN of the axotomized $(C)$ and normal $(D)$ side. $E$ and $F$, Fluorescence photomicrographs of the same SPN section showing FG-labeled preganglionic neurons (PGNs) $(E)$ and NOS-IR $(F)$ preganglionic neurons (PGNs). PGNs exhibiting NOS-IR (arrows) are indicated. Scale bar, $125 \mu \mathrm{m}$ for $A$ and $B, 80 \mu \mathrm{m}$ for $C$ and $D, 30 \mu \mathrm{m}$ for $E$ and $F$. 

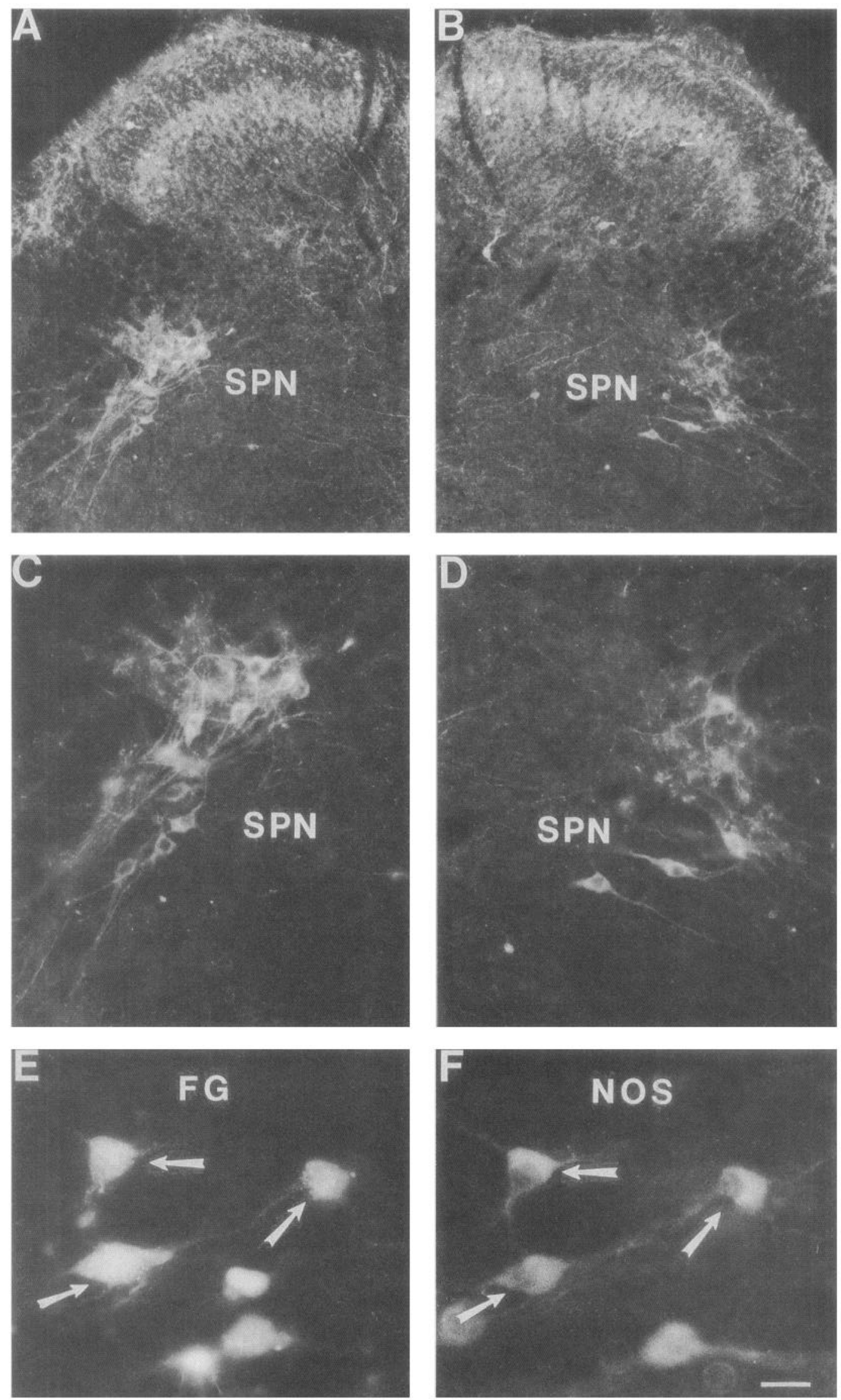
Table 3. Comparison between NADPH-diaphorase (NADPH-d) and NOS-IR in cells within the region of the sacral parasympathetic nucleus (SPN) in the L6-S1 spinal segments in control animals and in axotomized animals, ipsilateral (Ipsi) and contralateral (Contra) to axotomy

L6

\begin{tabular}{lll} 
& \multicolumn{2}{c}{ Cell profiles/section } \\
\cline { 2 - 3 } & NADPH-d & NOS-IR \\
\hline $\begin{array}{l}\text { Control } \\
\text { Axotomy }\end{array}$ & $6.5 \pm 0.6$ & $6.4 \pm 1.3$ \\
$\quad$ Ipsi & $8.9 \pm 0.5^{*}$ & $9.8 \pm 0.5^{*}$ \\
$\quad$ Contra & $5.1 \pm 0.6$ & $5.4 \pm 0.8$ \\
Control & $3.8 \pm 0.6$ & $4.5 \pm 0.4$ \\
Axotomy & & \\
Ipsi & $5.2 \pm 0.9$ & $5.3 \pm 0.3$ \\
Contra & $4.9 \pm 1.0$ & $5.3 \pm 0.5$
\end{tabular}

The numbers of NADPH-d-positive and NOS-IR neurons in the SPN were not significantly different in control animals and in axotomized animals contralateral to the axotomy. However, there was a significant increase $(p \leq 0.01)$ in the number of NADPH-d-positive and NOS-IR cells in the SPN ipsilateral to axotomy compared to the contralateral SPN in the L6 segment. No significant changes in the numbers of NADPH-d-positive or NOS-IR SPN cells were detected on cither side in the S1 segment. There was no significant difference in the numbers of neurons in the L6-S1 segments exhibiting NADPH-d activity or NOS-IR

lumbosacral DRG. The presence of these populations of axons in the MPG was confirmed by retrograde labeling of the neurons following injection of FG into the MPG.

\section{Neurons}

Dorsal root ganglia (DRG)

A differential distribution of NOS-IR was detected in DRG neurons at different levels of the spinal cord in control animals. Considerably larger numbers of NOS-IR neurons were present in T8, T10, and T12 DRGs (30-44 cell profiles/section; Figs. 1, 2) and rostral lumbar (L1-L2) DRGs (3-15 cell profiles/section) compared to caudal lumbosacral DRGs $(0.2-0.7$ cell profiles/section; Figs. 1, 2). A marked decrease in NOS-IR neurons occurred between the L1 and the L2 DRG (Fig. 1). At all levels (thoracic, lumbar, and sacral), NOS-IR neurons were small (15$20 \mu \mathrm{m})$ and medium $(25-32 \mu \mathrm{m})$ sized. Some of these neurons exhibited NOS-IR processes (Fig. 3A). Numerous NOS-IR axons as well as axonal varicosities occurred throughout the ganglia (Fig. 2A). Variations in NOS staining intensity (i.e., intense, moderate and light) were observed but this staining variation was not as dramatic as that observed for NADPH-d staining in DRG (Vizzard et al., 1993b,c).

Following removal of the MPG on one side the number of NOS IR neurons increased approximately 20 -fold in L6 and S1 DRGs ipsilateral to the ganglionectomy (Table 1, Fig. 2); however, there was not a significant change in the numbers of NOSIR cells ( $0.5-0.7$ cell profiles/section) in the contralateral DRGs, which had numbers equivalent to those in ganglia from control rats $(n=4 ; 0.6 \perp 0.1$ NOS-IR cell profiles/section in both L6 and SI DRG). After axotomy, the increase in NOS-IR in the ipsilateral L6 and S1 DRGs was highly significant ( $p \leq 0.001$; $\sim 11$ NOS-IR cell profiles/section). A smaller increase occurred in the Ll ganglia (18.7 \pm 1.8 NOS-IR cell profiles/section), whereas the numbers of NOS-IR neurons in L2 and L5 DRG on either side were not altered (Table 1). Following axotomy, NOS-IR was restricted primarily to small- and medium-sized DRG neurons as noted in control animals.
Table 4. Preganglionic neurons (PGN) exhibiting NOS-IR ipsilateral and contralateral to axotomy

\begin{tabular}{lllll} 
& & \multicolumn{2}{l}{ Cell profiles/section } & \multirow{2}{*}{$\begin{array}{l}\text { \% Colabel } \\
\text { (PGN with NOS) }\end{array}$} \\
\cline { 3 - 4 } SPN & & PGN & NOS-IR & \\
\hline L6 & Ipsi & $10.5 \pm 0.9$ & $9.4 \pm 1.6^{*}$ & $61.0 \pm 3.0^{*}$ \\
& Contra & $11.3 \pm 0.6$ & $4.3 \pm 0.5$ & $38.3 \pm 4.0$ \\
S1 & Ipsi & $7.7 \pm 0.9$ & $5.1 \pm 0.4$ & $37.7 \pm 1.4$ \\
& Contra & $9.0 \pm 0.6$ & $5.0 \pm 0.6$ & $36.7 \pm 2.4$
\end{tabular}

To determine the percentage of PGNs exhibiting NOS-IR, Fluorogold (FG) was injected into both major pelvic ganglia (MPG) ] week prior to the removal of the MPG on one side. These data are from a separate group of animals from those listed in Table 3. The numbers of FG-labeled PGNs and the numbers of NOS-IR cells in the region of the sacral parasympathetic nucleus (SPN) ipsilateral and contralateral to axotomy are indicated for the L6-SI spinal segments. Ipsilateral to axotomy, significantly $(p \leq 0.01$ ) increased numbers of NOS-IR cells are present in the region of the SPN in the L6 segment. Ipsilateral to axotomy in the L6 segment there was also a significant $(p \leq 0.01)$ increase in the percentage of PGNs exhibiting NOS-IR. No change in the numbers of NOS-IR cells in the SPN or the percentage of PGNs exhibiting NOS-IR was detected in the $\mathrm{S} 1$ segment.

To determine if MPG removal induced an increase in NOSIR in a specific population of DRG neurons, Fluorogold (FG) was injected into the MPG 1 week prior to its subsequent removal to label pelvic visceral afferent neurons. In the ipsilateral L6 and S1 DRG, an average of $34.1 \pm 2.2$ cell profiles/section and $22.8 \pm 1.0$ cell profiles/section, respectively $(n=5$ animals) were FG labeled after injection of dye into the MPG (Table 2, Fig. 3). In these ganglia an average of $37.0 \pm 4.0 \%$ (L6) and $20.6 \pm 2.2 \%(\mathrm{~S} 1)$, respectively, of FG-labeled pelvic afferent neurons were NOS IR compared to $1.1 \pm 0.5 \%$ (L6) and $2.5 \pm 1.4 \%$ (S1) contralateral to the axotomy (Table 2, Fig. 3). At rostral lumbar levels the percentage of pelvic visceral afferents normally expressing NOS-IR was higher than in L6-S1 DRG (Table 2). Following axotomy, a significantly greater percentage of dye-labeled pelvic visceral afferents in the L1 and L2 DRG ipsilateral to axotomy exhibited NOS-IR compared to the contralateral side (Table 2 ) and the percentage of $\mathrm{FG}$-labeled cells that were NOS-IR $(28-29 \%)$ was similar to the percentage of FG NOS-IR cells in L6-S1. The injection of FG into the MPG did not alter NOS expression since the numbers of NOSIR DRG cell profiles/section in DRG at various segmental levels were not significantly different in animals with or without the injection (Tables 1, 2).

\section{Spinal neurons}

As noted by other investigators (Dun et al., 1992, 1993; Valtschanoff et al., 1992a), in the rostral lumbar (L1--L2) and caudal lumbosacral (L6-S1) spinal cord, NOS-IR was detected in neurons at various sites: (1) around the central canal, (2) in the dorsal commissure, (3) in lamina II of the superficial dorsal horn (Fig. 4), and (4) in the region of the autonomic nuclei: intermediolateral cell column (IML; L1-L2) (Fig. 5) and the sacral parasympathetic nucleus (SPN; L6-S1) (Fig. 4). Intense NOSIR also occurred in fibers in the superficial laminae (I-II) of the dorsal horn and in the dorsolateral funiculus (Figs. $4 A, B ; 6$ ). NOS-IR processes from cells in the region of the IML or SPN coursed medially toward the central canal, laterally into the white matter, as well as ventrally along the lateral edge of the ventral horn (Figs. $4 A-D ; 5 A, C ; 7 A$ ). A few NOS-IR cells were located in the ventral horn (Fig. 6).

In the L6-S I spinal cord the numbers of NADPH-d-positive 

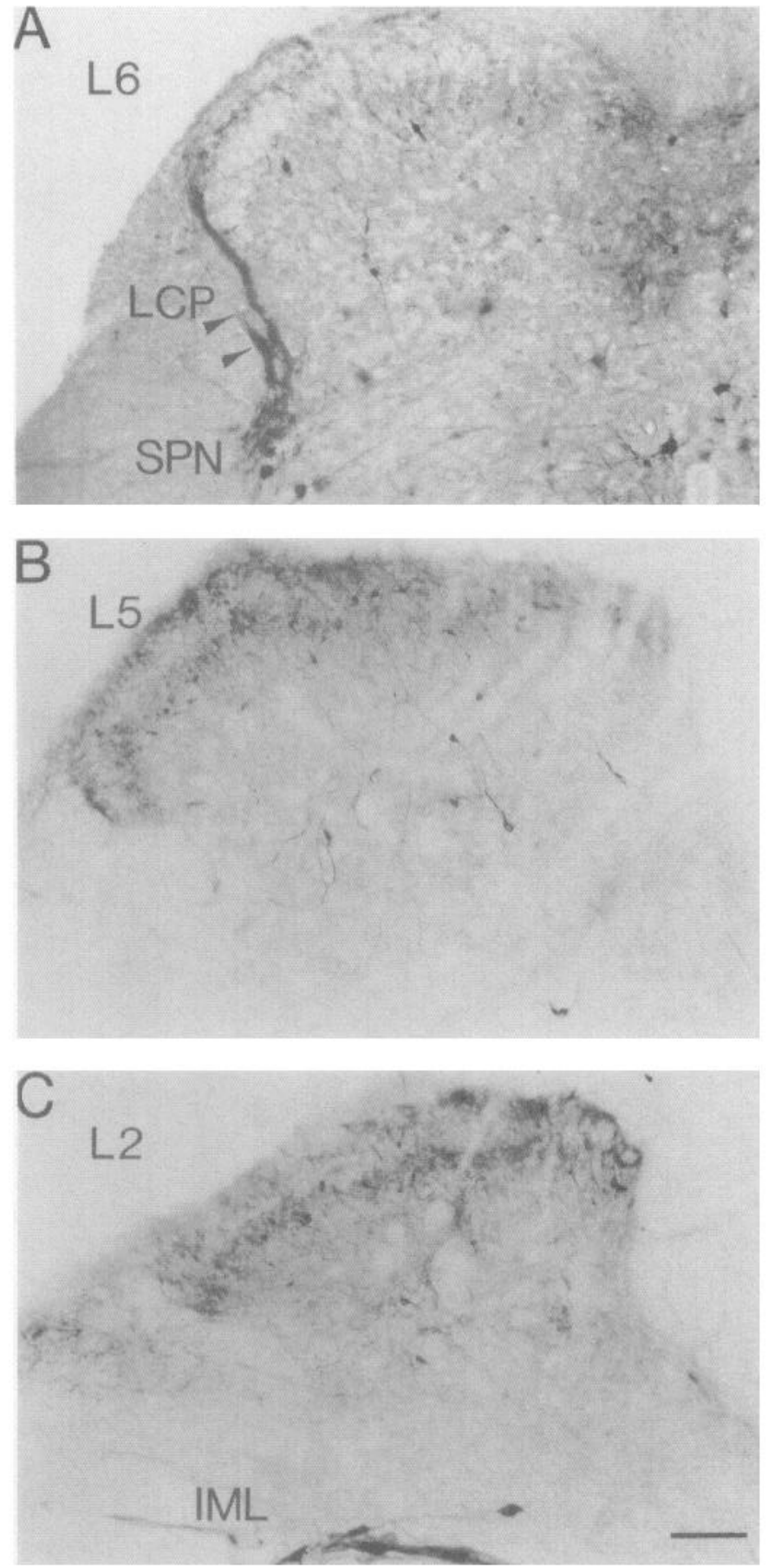

Figure 5. Distribution of NADPH-diaphorase (NADPH-d) activity at various levels of the spinal cord $(L 6, L 5, L 2)$. NADPH-d-positive cells and fibers are present in the superficial laminae of the dorsal horn in all segmental levels examined $(A, L 6 ; B, L 5 ; C, L 2)$. Some NADPH-dpositive cells are also present in deeper laminae of the dorsal horn. NADPH-d-positive cells are also present in the autonomic nuclei: the sacral parasympathetic nucleus $(S P N, A)$ in L6-S1 spinal segments and the intermediolateral cell column $(I M L, C)$ in thoracolumbar spinal segments. NADPH-d-positive fiber staining extending from Lissauer's tract along the lateral edge of the dorsal horn to the region of the SPN (i.e., lateral collateral pathway, $L C P$ ) was present only in L6-S1 spinal segments and not in adjacent $(L 5, B)$ or rostral lumbar $(L 2, C)$ segments. Scale bar, $150 \mu \mathrm{m}$ for $A-C$. (range, 3.8-6.5 cell profiles/section) and NOS-IR neurons (range, 4.5-6.4 cell profiles/section) in the region of the SPN at each segmental level in control animals and on the contralateral side of axotomized animals were not significantly different (Table 3). In addition, the numbers of NADPH-d-stained neurons were equivalent to the numbers of NOS-IR neurons (Table 3 ). However, ipsilateral to axotomy the numbers of NADPH-d and NOS-IR cells in the region of the SPN in the L6 spinal segment were significantly increased (Table 3 , Fig. $4 C, D$ ). For example, on the side contralateral to the axotomy an average of $5.1 \pm$ 0.6 cell profiles/section and $5.4 \pm 0.8$ cell profiles/section were NADPH-d positive and NOS-IR, respectively, whereas the ipsilateral side had an average of $8.9 \pm 0.5$ cell profiles/section and $9.8 \pm 0.5$ cell profiles/section that were NADPH-d positive and NOS-IR, respectively. The differences between the two sides were statistically significant $(p \leq 0.01)$. However, axotomy did not alter the numbers of NADPH-d/NOS-IR cells in the region of the SPN in the SI segment (Tables 3, 4). Similarly, no difference in the numbers of NADPH-d-positive cells in the region of the IML in the $\mathrm{L} 1-\mathrm{L} 2$ segments was detected after axotomy ( $\sim 8$ cell profiles/section on each side in $\mathrm{Ll}$ and 6 cell profiles/section on each side in L2).

To determine the distribution of NOS-IR in preganglionic neurons (PGNs) projecting to the pelvic viscera, FG was injected into the MPG bilaterally 1 week prior to its removal to retrogradely label preganglionic neurons in the spinal cord. Within the region of the SPN in the L6 segment, an average of $10.5 \pm$ 0.9 cell profiles/section and $11.3 \pm 0.6$ cell profiles/section $(n$ $=3$ animals) ipsilateral and contralateral to axotomy, respectively, were FG labeled (Table 4). All NOS-IR cells in the region of the SPN in both the L6 and S1 spinal segments were FG labeled (Fig. 4E,F). On the contralateral side, $38.3 \pm 4.0 \%$ of PGNs in the L6 spinal segment were colabeled with NOS-IR. Ipsilateral to axotomy, a significantly greater percentage (61.0 $\pm 3.0 \% ; p \leq 0.01$ ) of PGNs exhibited NOS-IR (Table 4). In contrast, in the S1 spinal segment, the percentage of PGNs exhibiting NOS-IR was unaffected by axotomy (Table 4). The numbers of NADPH-d-positive or NOS-IR cell profiles/section in the region of the SPN in control animals without FG (Table 3) are not significantly different from those in animals injected with FG (Table 4).

Small numbers of FG-labeled sympathetic preganglionic neurons (PGNs) were detected in the IML at L1-L2 spinal levels following injection of dye into the MPG. In the L1 segment, an average of $1.3 \pm 0.1$ cell profiles/section and $1.2 \pm 0.1$ cell profiles/section ( $n=3$ animals) ipsilateral and contralateral to axotomy, respectively, were FG labeled. Ipsilateral and contralateral to axotomy $91.6 \pm 6.0 \%$ and $91.0 \pm 8.0 \%$, respectively, of the PGNs exhibited NADPH-d activity. In the L2 segment, a slightly greater number of FG-labeled cells were present in the IML (ipsilateral, $2.2 \pm 0.1$ cell profiles/section; contralateral, $2.1 \pm 0.2$ cell profiles/section). Axotomy did not influence the percentage of FG-labeled cells that were NADPH-d positive (ipsilateral, $90.0 \pm 2.8 \%$; contralateral, $93.0 \pm 1.5 \%$ ). In the rat, preganglionic neurons are also abundant in the region dorsal to the central canal between T13 and L2 where they form the dorsal commissural nucleus (Hancock and Peveto, 1979). In the L1 and L2 segments, respectively, an average of $3.1 \pm 0.3$ and $3.3 \pm$ $0.3 \mathrm{FG}$-labeled cell profiles/section were observed in the dorsal commissural nucleus. A similar percentage of these preganglionic neurons were also NADPH-d positive $(n=1 ; \mathrm{L1}, 88 \%$; L2, 96\%). 

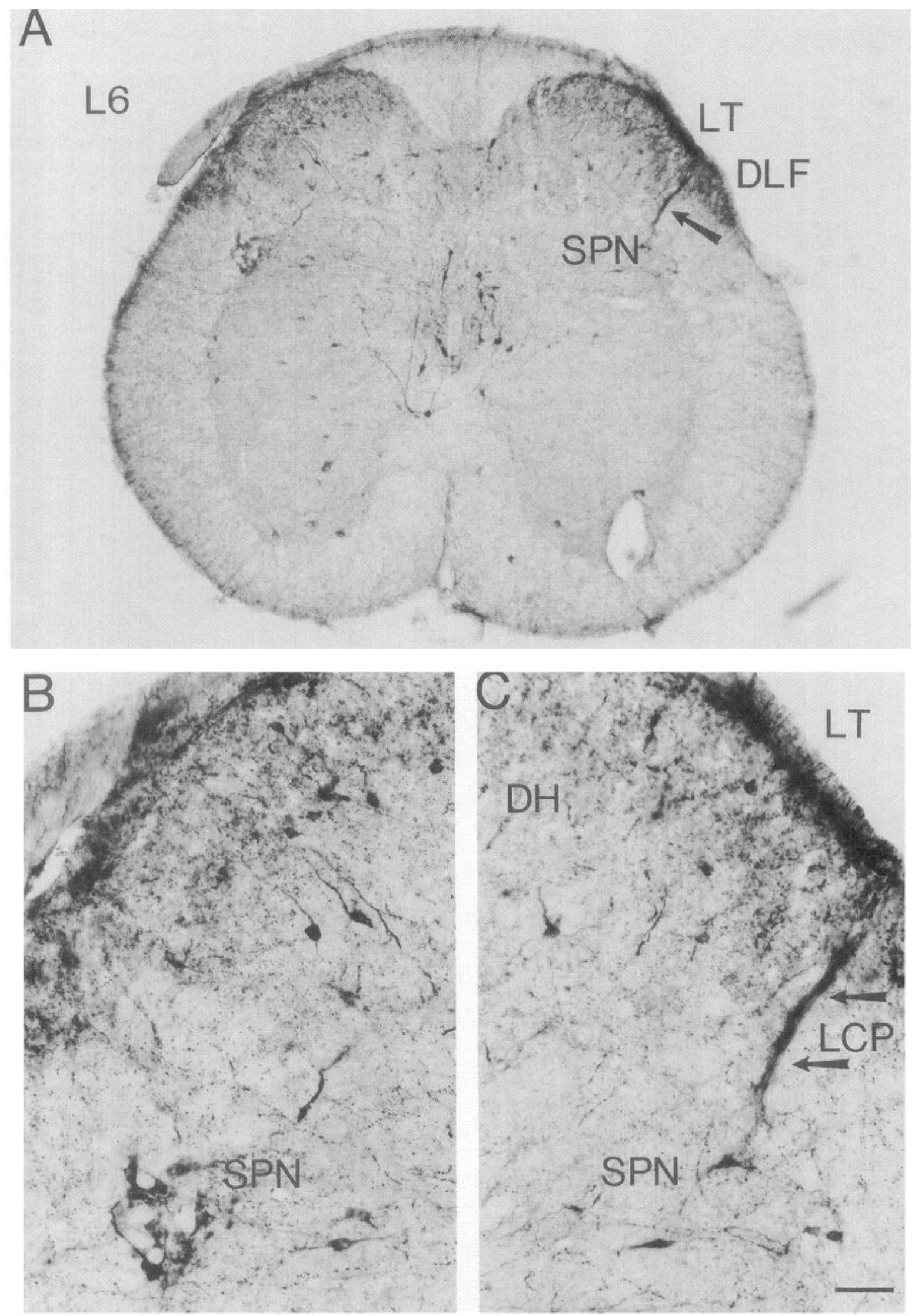

Figure 6. Bright-field photomicrographs showing the effect of unilateral (right side) axotomy on nitric oxide synthase immunoreactivity (NOSIR) in a transverse section of the L6 spinal segment. A, Low-power photomicrograph showing NOS-IR neurons and fibers bilaterally in the superficial laminae of the dorsal horn, in the region of the sacral parasympathetic nucleus $(S P N)$, and around the central canal. A few NOS-IR cells are present 


\section{Fibers}

\section{Caudal lumbosacral spinal cord}

As described previously (Vizzard et al., 1993a,c, 1994a), prominent NADPH-d activity in the lumbosacral (L6-S1) segments occurred in afferent fibers within and extending from Lissauer's tract along the lateral edge of the dorsal horn in laminae $I$ and $\mathrm{V}$ to the region of the SPN (Fig. 5A); however, these afferent projections do not exhibit NOS-IR (Vizzard et al., 1994b) (Fig. $6 A, B)$. NADPH-d afferent projections were not present in every section, suggesting that they occur intermittently along the rostral-caudal axis as noted for visceral afferent projections labeled with wheat germ agglutinin horseradish peroxidase (WGA-HRP) or horseradish peroxidase (HRP) (Steers et al., 1991). The general location of the NADPH-d fibers in lamina I and its selective segmental distribution are very similar to the central projections of pelvic nerve visceral afferents designated the lateral collateral pathway of Lissauer's tract (LCP) (Morgan et al., 1981; de Groat et al., 1986). These bundles were not present in L5 or S2 spinal segments. Following axotomy, no obvious change in the appearance or segmental distribution of NADPH-d activity in the LCP was detected on either side of the L6-SI spinal cord. However, following axotomy, NOS-IR fibers were detected along the lateral edge of the dorsal horn extending from Lissauer's tract to the region of the SPN on the ipsilateral side of the L6 and S1 spinal segments (Fig. 6A,C). Increased NOS-IR was also often detected in Lissauer's tract as well as in the dorsolateral funiculus following axotomy (Fig. 6). These NOS-IR fibers in the LCP were not present in adjacent spinal segments (L4, L5, or $\mathrm{S} 2$ ), nor were they present at rostral lumbar (L1-L2) spinal levels before or after axotomy. The NOS-IR fiber staining in the LCP was not present in every transverse section. In addition, many sections did not contain the entire fiber bundle from Lissauer's tract to the base of the dorsal horn, possibly due to a rostrocaudal orientation of the bundle, which carried it out of the plane of the section. Thus, in some sections, NOS-IR fiber staining was clustered immediately dorsal to SPN cells or was intermingled with SPN cells (Figs. $4 C, 7$ ). NOS-IR fibers did not extend from the LCP medially to the region of the dorsal commissure as noted for WGA-HRP-labeled pelvic visceral afferents (Nadelhaft and Booth, 1984; Steers et al., 1991). In sayittal sections, ipsilateral to axotomy, clusters of NOS-IR fibers were located dorsal to the SPN and also intermingled with cells in the region of the SPN (Fig. $7 B$ ). In contrast, no NOS-IR fibers were located in a similar region of the SPN on the contralateral side (Fig. $7 D$ ). NOS-IR cells were randomly distributed throughout the region of the SPN. Some processes of these SPN cells coursed dorsally into the NOS-IR fibers. Processes from SPN cells projecting into the NOS-IR fiber bundle were easily distinguished from the latter since the NOS-IR fiber bundles were more diffuse in appearance in contrast to the distinct processes of SPN cells. NOS-IR on the axotomized side was more prominent in fibers coursing rostrocaudally along the dorsal and dorsolateral edge of the dorsal horn (Fig. $7 C$ ). No obvious changes in NOS-IR in cells or fibers were detected on either side in the remainder of the dorsal horn.

\section{Discussion}

The present study revealed that under normal conditions NOSIR is differentially expressed in afferent and preganglionic efferent neurons (PGNs) projecting to the pelvic viscera. Peripheral axotomy markedly increased NOS expression in both types of visceral neurons; however, the increase was most prominent in afferent neurons in caudal lumbosacral dorsal root ganglia (DRG), which normally had very few NOS-IR cells. Although NOS-IR was detected in DRG cells at various segmental levels, it was present in considerably more cells at thoracic (T8, T10, $\mathrm{T} 12$ ) and rostral lumbar (L1) levels in comparison to caudal lumbosacral (L5-S1) levels. In agreement with a previous study on NADPH-d activity in DRG of the rat (Aimi et al., 1991), the present results suggest a more prominent role for NO in thoracic versus lumbosacral afferent pathways.

Under normal conditions NOS-IR was present in considerable numbers of L6-S1 PGN but only in a small percentage of visceral afferent neurons at this segmental level. The relationship between NOS-IR and NADPH-d activity was also different in the two types of neurons. The two histochemical markers were present in a similar percentage of PGN (Vizzard et al., 1993c), whereas in visceral afferent neurons NADPH-d staining was much more common than NOS-IR (Vizzard et al., 1994b). Thus, NADPH-d activity is a reliable marker for NOS-IR in PGN but not in visceral afferent neurons.

Two to four weeks following peripheral axotomy, NOS expression markedly increased in lumbosacral afferents and in L6 PGN. However, the increase was most striking after axotomy in the L6-S1 afferent neurons (20-fold increase in number) and less prominent in L6 PGN (2-fold increase in number). The percentage of L6-S1 and L1-L2 visceral afferent neurons exhibiting NOS-IR was similar after axotomy, $20-37 \%$ and $28-29 \%$, respectively. However, the percentage increase in NOS-IR in L6-S I visceral afferents was much greater (8-34-fold) than that in L1-L2 visceral afferents (3-5-fold) since NOS-IR was present in a higher percentage of L1-L2 neurons in control animals (6$9 \%$ vs $1-2.5 \%$ ). The fact that not all visceral afferent neurons express NOS-IR after axotomy could reflect the inability of some neurons to increase NOS expression or may indicate that the neurons that did not respond were not completely axotomized (i.e., they may have axonal branches that project to areas outside the MPG, such as satellite ganglia). Clearly, the cells sent axons into the MPG since they were labeled by dye injections; however, these axons might represent only one part of the peripheral axonal projection of the cells.

NOS upregulation might require transection of the entire peripheral axonal pathway. This view is supported by a comparison of the present findings with previous observations (Vizzard et al., 1993a) that revealed that ventral rhizotomy increased the percentage of L6 and SI PGNs exhibiting NADPH-d staining.

$\leftarrow$

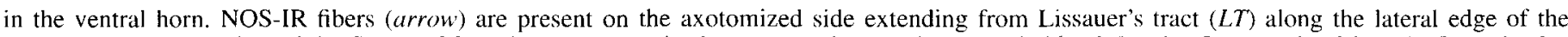

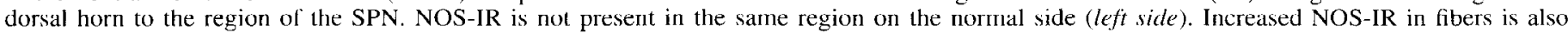

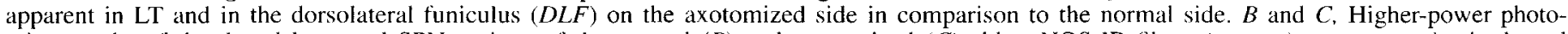

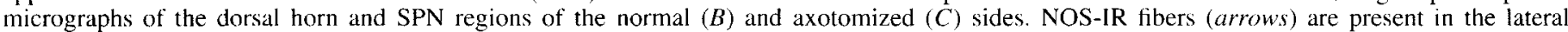

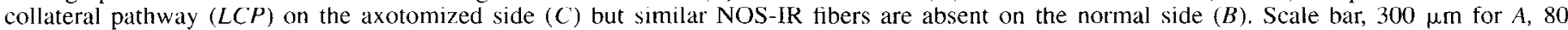
$\mu \mathrm{m}$ for $B$ and $C$. 

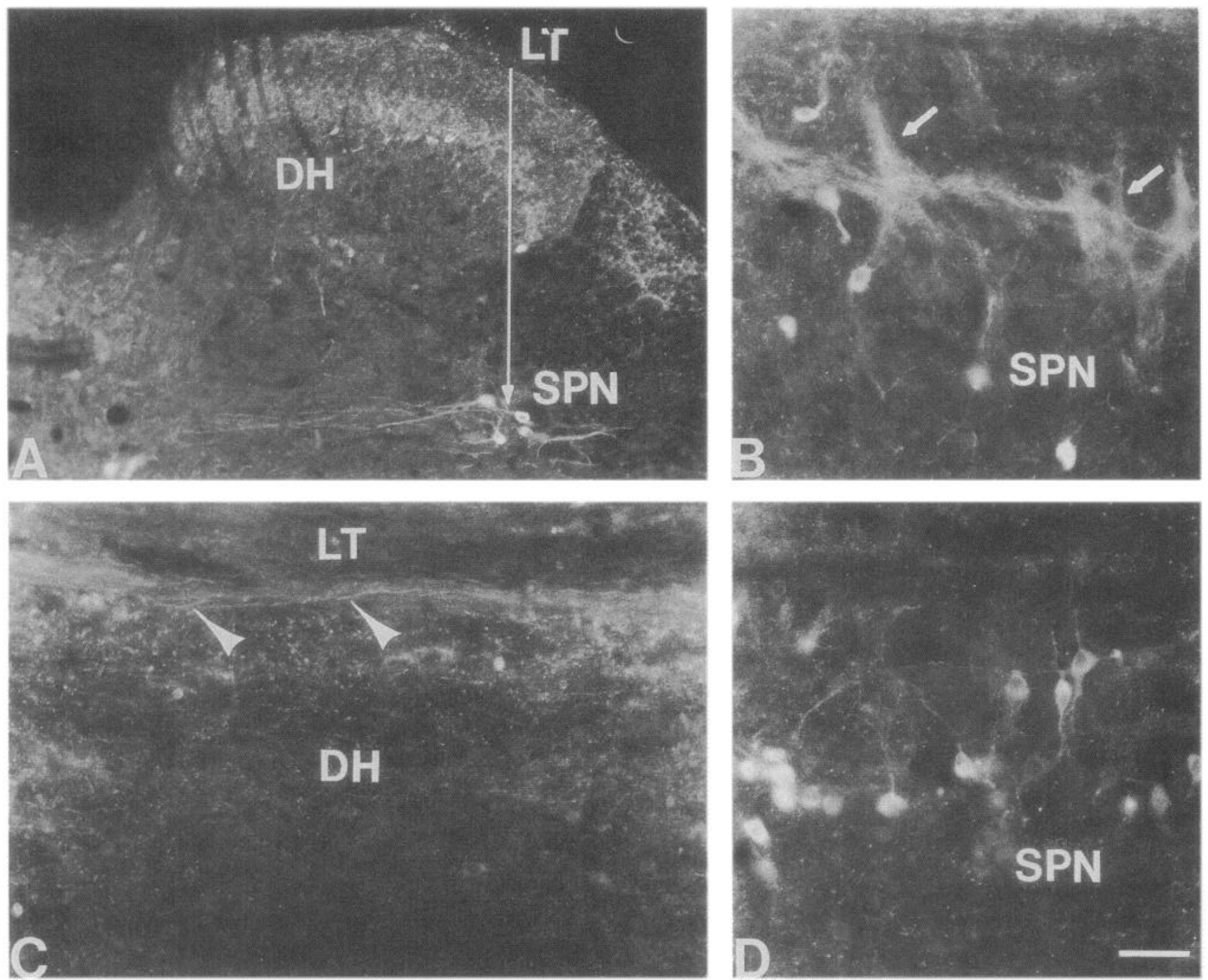

Figure 7. Fluorescence photomicrographs showing the distribution of NOS-IR in sagittal sections of the L6 spinal cord ipsilateral and contralateral to axotomy. A. Orientation figure of a transverse section from a control animal of the L6 spinal cord showing the approximate location (vertical white line) of the sections in $B-D, B$ and $C$ are in the same plane of section, with $C$ illustrating only the dorsal part (Lissauer's tract, $L T$; dorsal horn, $D H$ ) of the section and $B$ illustrating the ventral part near the region of the sacral parasympathetic nucleus $(S P N)$. $B$. Ipsilateral to axotomy, clusters of NOS-IR fibers (arrows) are located dorsal to the SPN and also intermingled with cells in the region of the SPN. In contrast, no NOSIR fibers are located in a similar region of the SPN on the contralateral side $(D)$. $C$. NOS-IR fibers (arrowheads) projecting rostrocaudally within LT are present on the axotomized side along the dorsal and dorsolateral edge of the DH. Scale bar, $150 \mu \mathrm{m}$ for $A, 135$ for $B$ and $D, 190 \mu \mathrm{m}$ for $C$,

As noted above, NADPH-d reflects NOS-IR in PGNs. Thus, S1 $\mathrm{PGN}$ can respond to complete axotomy with NOS upregulation. However, since MPG removal in the present study did not elicit an increase in NOS-IR in SI PGN, it must be concluded that these neurons send axonal branches to sites in the pelvic plexus outside the MPG and that these surviving axons are sufficient to prevent NOS upregulation. It is noteworthy that even with complete axotomy some PGN neurons (e.g., sacral PGN in the cat) (Vizzard et al., 1994a) do not express NADPH-d/NOS-IR. Similarly, sciatic nerve transection in the monkey is without effect on NOS expression in either the DRG or spinal cord (Zhang et al., 1993), whereas sciatic nerve transection in the rat results in dramatic changes in NOS expression in each of these areas (Verge et al., 1992; Zhang et al., 1993). Following axotomy, 30$50 \%$ of neurons in cranial motor nuclei (i.e., hypoglossal nucleus, dorsal motor nucleus, and motor nucleus of the facial nerve) ipsilateral to axotomy express NADPH-d/NOS-IR (Yu, 1994).
Thus, various factors may affect injury-induced NOS expression.

Alterations in the expression of other genes are known to occur in DRG cells following peripheral nerve injury. Downregulation of substance $\mathrm{P}$ (Jessel et al., 1979; Neilsch and Keen, 1989), calcitonin gene-related peptide (Noguchi et al., 1990), somatostatin (McGregor et al., 1984), and laminin-binding protein (Ren et al., 1993) has been reported in DRG cells following peripheral axotomy. On the other hand, increase in expression of vasoactive intestinal polypeptide (VIP) (McGregor et al., 1984), galanin (Hökfelt et al.. 1987), neuropeptide Y (NPY) (Wakisaka et al., 1991), and growth-associated protein (GAP43) (Woolf et al., 1990; Tang et al., 1994) has been detected in axotomized DRG cells. Following injury NOS mRNA is colocalized in DRG cells with various peptides (VIP, galanin, and NPY) that do not normally coexist with NOS (Verge et al. 1992). 
In addition to the upregulation of NOS-IR in the L6-S1 DRG neurons following axotomy, NOS-IR fibers extending along the lateral edge of the dorsal horn from Lissauer's tract (LT) to the region of the SPN also became obvious in these same segments on the side of the axotomy (Fig. 6), suggesting that increased amounts of NOS enzyme are transported centrally into the afferent nerve fibers in the LCP following peripheral nerve injury. This fiber tract resembles the central projections of pelvic visceral afferents (i.e., lateral collateral pathway, LCP) and NADPH-d-containing primary afferents (Fig. 5) (Vizzard et al., 1993a,c, 1994a). In contrast, at other spinal levels where NOSIR was present in numerous DRG cells before axotomy (i.e., L1), NOS-IR fibers were not detected along the lateral edge of the dorsal horn despite a significant increase in the percentage of visceral afferents exhibiting NOS IR after axotomy. Other investigators (Zhang et al., 1993) have reported increases in NOS-IR fibers in superficial lamina II of the L4-L5 dorsal horn following sciatic nerve transection (Zhang et al., 1993).

Prior to axotomy, NADPH-d-positive fibers in the LCP of the rat, cat (de Groat et al., 1993; Vizzard et al., 1994c), and dog (Vizzard et al., unpublished observations) do not exhibit NOSIR. This mismatch between the two histochemical markers might be related to several factors, some of which could be technical, such as (1) the NOS protein in the afferent neurons might he an isoform not detected by the antibody to rat cerebellar NOS (Dawson et al., 1993) or (2) the thresholds for detection of NADPH-d and NOS staining are different. However, the present results suggest that a real biochemical difference exists between NADPH-d activity and NOS-IR in the LCP. In the normal rat, very few cells in the L6-S1 DRG are NOS-IR, which is reflected in the absence of NOS-IR in the central projections of these cells. It is only after axotomy with the subsequent increase in NOS-IR in the L6-SI DRG that NOS-IR fibers are observed in the LCP. Although there are numerous instances of colocalization of NADPH-d activity and NOS-IR in the nervous system (Bredt et al., 1991; Dawson et al., 1991; Belai et al., 1992; Saffrey et al., 1992; Schmidt et al., 1992; Ward et al., 1992; Young et al., 1992; Fischer et al., 1993) therc arc also arcas in the CNS (Hope et al., 1991; Lee et al., 1993; Meller and Gebhart, 1993) as well as in other tissues (Dawson et al., 1991; Schmidt et al., 1992) where NADPH-d activity does not appear to reflect NOS-IR. Thus, the NADPH-d activity in afferent fibers in the LCP demonstrated in this and previous studies in the rat (Vizzard et al., 1993a,c) and cat (de Groat et al., 1993; Vizzard et al., 1994a) may reflect the presence of enzymes other than NOS and indicates that NADPH-d activity is not always a specific histochemical marker for NO-containing neural structures.

Previous experiments in this laboratory demonstrated that $49.4 \pm 12.7 \%$ of dye-labeled preganglionic neurons in the L6 spinal segment were NADPH-d positive (Vizzard et al., 1993c). In addition, when cells in the region of the SPN were grouped into three categories (i.e., intense, moderate, light) based upon intensity of NADPH-d staining, 38\% of these cells were categorized as intensely NADPH-d stained (Vizzard et al., 1993a). The results of the present experiments have demonstrated that a similar percentage $(38.3 \pm 4.0 \%)$ of preganglionic neurons in the L6 spinal segment exhibit NOS-IR. A considerably higher percentage $(63-88 \%)$ of sympathetic preganglionic neurons are NADPH-d/NOS positive (Anderson, 1992; Saito et al., 1994).

Since the SPN contains interneurons and projection neurons as well as PGN (Birder et al., 1990, 1994; McNeill et al., 1993), the question arises as to which cell populations in the region of the SPN are NOS-IR. In the present experiments, virtually all NOS-IR cells in the SPN of the L6-S1 spinal cord were identified as parasympathetic PGNs on the basis of retrograde labeling from the MPG. Thus, NOS-IR must be limited to parasympathetic PGNs and not be present in projection cells and presumptive interneurons that are intermingled with and located immediately dorsal to PGN (de Groat et al., 1994). This is consistent with the previous demonstration (Anderson, 1992) that virtually all NADPH-d-containing cells in the intermediolateral cell column are sympathetic PGNs.

The relationship between pelvic visceral afferent projections and neurons in the SPN was obvious following axotomy when NOS-IR was upregulated in tibers in the LCP. Following axotomy, NOS-IR fibers were detectable in the LCP extending from LT to the region of the SPN where they are distributed among the dye-labeled and NOS-IR PGNs as well as dorsally to these neurons. Recent experiments from this laboratory using pseudorabies virus (PRV) tracing techniques (de Groat et al., 1994; Vizzard et al., 1994d) have demonstrated that the region of the SPN is heterogeneous and consists of several cell populations (i.e., preganglionic neurons and interneurons). These transneuronal tracing results are consistent with conventional tract-tracing methods (Birder et al., 1990, 1994; McNeill et al., 1993) described in the preceding paragraph indicating that interneurons were primarily located dorsal to dye-labeled PGN (de Groat et al., 1994). Previous axonal tracing and c-fos studies have also revealed that spinal tract cells are intermingled with the PGNs in the L6-S1 spinal cord (Birder et al., 1990; McNeill et al., 1993) and that spinal tract cells, interneurons, and PGNs are synaptically activated by stimulation of bladder afferents (Birder et al., 1990). The present experiments show that pelvic visceral afferent neurons that upregulate NOS after peripheral axotomy send projections in the LCP that terminate in close proximity to interneurons and tract neurons as well as PGNs in the region of the SPN.

The mechanism by which NOS-IR is upregulated in visceral afferents and PGNs following axotomy is uncertain but may involve one of the following signals: (1) interruption of a continuous flow of neurotrophic factors (e.g., NGF) from peripheral target organs (i.e., bladder, colon, sex organs) that normally prevent the expression of NOS; axotomy eliminates trophic factor inhibition and results in the upregulation of NOS; (2) chemicals taken up by injured axons from the extracellular environment may act to upregulate NOS expression; or (3) regulatory proteins synthesized by the cell body and subsequently transported in the axons may be altered due to axonal damage resulting in retrograde transport of the altered protein to the cell body, where it can be incorporated into the nucleus and affect gene expression (Walters, 1994; Walters et al., 1994).

The function of NO formed by enhanced expression of NOS in visceral afferent cells and PGNs following axotomy is uncertain. It has been suggested that induction of NOS-IR in motoneurons following ventral root avulsion is involved in the subsequent death of lesioned motoneurons because pretreatment with an NOS inhibitor significantly increases the numbers of surviving motoneurons (Wu and Li, 1993). Increased expression of NOS-IR in somatic afferents after sciatic nerve injury has been suggested to enhance regeneration by increasing blood flow (Verge et al., 1992). In addition, it has been suggested that NO may be involved in the gencration of spontancous discharges in deafferentated DRG because L-NAME, an NOS inhibitor, sup- 
presses ongoing activity in spinal rootlets connected to an axotomized peripheral nerve (Wiesenfeld-Hallin et al., 1993).

\section{References}

Aimi Y, Fujimara M, Vincent SR, Kimura H (199I) Localization of NADPH-diaphorase-containing neurons in sensory ganglia of the rat. J Comp Neurol 306:382-392.

Anderson CR (1992) NADPH diaphorase-positive neurons in the rat spinal cord include a subpopulation of autonomic preganglionic neurons. Neurosci Lett 139:280-284.

Belai A, Schmidt HHHW, Hoyle CHV, Hassall CJS, Saffrey MJ, Moss J, Förstermann U, Murad F, Burnstock G (1992) Colocalization of nitric oxide synthase and NADPH-diaphorase in the myenteric plexus of the rat gut. Neurosci Lett 143:60-64.

Birder LA, Roppolo JR, de Groat WC (1990) C-fos as a marker for subsets of visceral second order neurons in the rat lumbosacral spinal cord. Soc Neurosci Abstr 16:703.

Birder LA, Roppolo JR, Erickson VL, de Groat WC (1994) Increased c-fos expression in spinal tract neurons and preganglionic neurons after irritation of the lower urinary tract in the rat. J Comp Neurol, in press.

Blottner D, Baumgarten H (1992) Nitric oxide synthetase (NOS) containing sympathoadrenal cholinergic neurons of the rat IML-cell column: evidence from histochemistry, immunohistochemistry and retrograde labeling. J Comp Neurol 316:45-55.

Bredt DS, Hwang PM, Snyder SH (1990) Localization of nitric oxide synthase indicating a neural role for nitric oxide. Nature 347:768770 .

Bredt DS, Glatt CE. Hwang PM. Fotuhi M, Dawson TM, Snyder SH (1991) Nitric oxide synthase protein and mRNA are discretely localized in neuronal populations of the mammalian CNS together with NADPH diaphorase. Neuron 7:615-624.

Burnett AL, Lowenstein CJ, Bredt DS, Chang TSK, Snyder SH (1992) Nitric oxide: a physiolngic mediator of penile erection. Science 257: 401-403.

Dail WG, Galloway B, Bordegaray J, Walton G (1992) Functional and histochemical evidence for the involvement of nitric oxide in regulation of penile erectile tissue. Soc Neurosci Abstr 18:128.

Dawson TM, Bredt DS, Fotuhi M, Hwang PM, Snyder SH (1991) Nitric oxide synthase and neuronal NADPH diaphorase are identical in brain and peripheral tissues. Proc Natl Acad Sci USA 88:7797-7801.

Dawson TM, Steiner JP, Mon JA, Snyder SH (1993) Multiple isoforms of neuronal nitric oxide synthase. Soc Neurosci Abstr 19:905.

de Groat WC, Booth AM (1993) Synaptic transmission in pelvic ganglia. In: The autonomic nervous system, Vol 3, Chap 8 (Maggi CA, ed), pp 291-348. Switzerland: Harwood.

de Groat WC, Kawatani M, Hisamitsu T, Booth AM, Roppolo JR, Thor $K$, Tuttle P, Nagel I (1986) Neural control of micturition: the role of neuropeptides. J Auton Nerv Sys [Suppl] 369-387.

de Groat WC, Vizzard MA, Erdman SL, Erickson VL, Stewart RJ, Roppolo JR, Förstermann U (1993) Differential distribution of NADPH-diaphorase (NADPH-d) and nitric oxide synthase (NOS) immunoreactivity in the thoracolumbar-sacral spinal cord of the cat. Soc Neurosci Abstr 19:510.

de Groat WC, Yoshimura N, Roppolo JR, Erdman SL, Erickson VL, Yu YB, Card JP, Vizzard MA (1994) Differentiation of bladder preganglionic (PGN) and interneurons (INTs) in the L6-SI spinal cord of the adult rat using pseudorabies (PRV) and Fluorogold (FG) dye tracing techniques. Soc Neurosci Abstr 20:114.

Dun NJ. Dun SL, Förstermann U, Tseng LF (1992) Nitric oxide synthase immunoreactivity in the rat spinal cord. Neurosci Lett 147:217220 .

Dun NJ, Dun SL, Wu SY, Förstermann U, Schmidt HHHW, Tseng LF (1993) Nitric oxide synthase immunoreactivity in the rat, mouse, cat and squirrel monkey spinal cord. Neuroscience 51:845 857

Fischer A, Mundel P, Preissler U, Philippin B, Kummer W (1993) Nitric oxide synthase in guinea pig lower airway innervation. Neurosci Letl 149:157-160.

Gonzalez MF, Sharp FR, Sagar SM (1987) Axotomy increases NADPH-diaphorase staining in rat vagal motor neurons. Brain Res Bull 18:417-427

Hancock MB, Peveto CA (1979) A preganglionic autonomic nucleus in the dorsal grey commissure of the lumbar spinal cord of the rat. $\mathrm{J}$ Comp Neurol 183:65-72

Hökfelt T, Wiesenfeld-Hallin Z. Villar M, Melander T (1987) Increase of galanin-like immunoreactivity in rat dorsal root ganglion cells after peripheral axotomy. Neurosci Lett 83:217-220.

Hope BT, Michael GJ, Knigge KM, Vincent SR (1991) Neuronal NADPH diaphorase is a nitric oxide synthase. Proc Natl Acad Sci USA 88:2811-2814.

Jessel T, Tsunoo A, Kanazawa I, Otsuka M (1979) Substance P: depletion in the dorsal horn of rat spinal cord after section of the peripheral processes of primary sensory neurons. Brain Res 168:247259

Keast JR (1992) A possible neural source of nitric oxide in the rat penis. Neurosci Lett 143:69-73.

Keast JR, de Groat WC (1989) Immunohistochemical characterization of pelvic neurons which project to the bladder, colon or penis in rats. J Comp Neurol 288:387-400

Lee J H, Price RH, Williams FG, Mayer B, Beitz AJ (1093) Nitric oxide synthase is found in some spinothalamic neurons and in neuronal processes that appose spinal neurons that express Fos induced by noxious stimulation. Brain Res 608:324-333.

McGregor GP, Gibson SJ, Sabate IM, Blank MA, Christofides ND, Wall PD, Polak JM, Bloom SR (1984) Effect of peripheral nerve section and nerve crush on spinal cord neuropeptides in the rat; increased VIP and PHI in the dorsal horn. Neuroscience 13:207-216.

McNeill DL, Papka RE, Harris CH (1992a) CGRP immunoreactivity and NADPH-diaphorase in afferent nerves of the rat penis. Peptides 13:1239-1246.

McNeill DL, Traugh NE Jr, Vaidya AM, Hua HT, Papka RE (1992b) Origin and distribution of NADPH-diaphorase-positive neurons and fibers innervating the urinary bladder of the rat. Neurosci Lett 147: $33-36$.

McNeill DL, Papka RE, Hamilton MO, O’Donoghue DL, Mayer B (1993) Relationship of nitric oxide synthase (NOS) to L6/S I spinal neurons that project to the pontine micturition center (PMC) in the rat. Soc Neurosci Abstr 19:509.

Meller ST, Gebhart GF (1993) Nitric oxide (NO) and nociceptive processing in the spinal cord. Pain 52:127-136.

Morgan C, Nadelhaft I, de Groat WC (1981) The distribution of visecral primary afferents from the pelvic nerve within Lissauer's tract and the spinal gray matter and its relationship to the sacral parasympathetic nucleus. J Comp Neurol 201:415-440

Nadelhaft I, Booth AM (1984) The location and morphology of preganglionic neurons and the distribution of visceral afferents from the rat pelvic nerve: a horseradish peroxidase study. J Comp Neurol 226: 238-245.

Neilsch U, Keen P (1989) Reciprocal regulation of tachykinin- and vasoactive intestinal peptide-gene expression in rat sensory neurones following cut and crush injury. Brain Res 481:25-30

Noguchi K, Senba E, Morita Y, Sato M, Tohyama M (1990) AlphaCGRP and beta-CGRP mRNAs are differentially regulated in the rat spinal cord and dorsal root ganglia. Mol Brain Res 7:299-304.

Papka RE, McNeill DL (1992) Distribution of NADPH-diaphorasepositive nerves in uterine cervix and neurons in dorsal root and paracervical ganglia of the female rat. Neurosci Lett 147:224-228.

Pitkanen A, Amaral DG (1991) Distribution of reduced nicotinamide adenine dinucleotide phosphate diaphorase (NADPH-d) cells and fibers in the monkey amygdaloid complex. J Comp Neurol 313:326348.

Ren K, Kibbey MC, Kleinman HK, Ruda MA (1993) I10/140 lamininbinding protein immunoreactivity in spinal dorsal root ganglia: a capsaicin-insensitive reduction induced by constriction injury of the sciatic nerve in rat. $\mathbf{J}$ Neurosci Res 35:227-236.

Saffrey MJ, Hassall CJS, Hoyle CHV, Belai A, Moss J, Schmidt HHHW, Förstermann U, Murad F. Burnstock G ( 1992 ) Colocalization of nitric oxide synthase and NADPH-diaphorase in cultured myenteric neurones. Neuroreport 3:333-336.

Saito S, Kidd GJ, Hanley DF, Bredt DS, Dawson TM, Wilson D, Traystman RJ, Snyder SH (1992) Rat spinal cord neurons contain nitric oxide synthase. Soc Neurosci Abstr 18:858.

Saito S, Kidd GJ, Trapp BD, Dawson TM, Bredt DS, Wilson DA, Traystman RJ, Snyder SH, Hanley DF (1994) Rat spinal cord neurons contain nitric oxide synthase. Neuroscience 59:447-456.

Santer RM, Symons D (1993) Distribution of NADPH-diaphorase activity in rat paravertebral, prevertebral and pelvic sympathetic ganglia. Cell Tissue Res 271:115-121.

Scherer-Singler U, Vincent SR, Kimura H, McGeer EG (1983) Dem- 
onstration of a unique population of neurons with NADPH diaphorase histochemistry. J Neurosci Methods 8:229-234.

Schmidt HHHW, Gagne GD, Nakan M, Pollock JS, Miller MF, Murad F (1992) Mapping of neural nitric oxide synthase in the rat suggests frequent colocalization with NADPH diaphorase but not with soluble guanylyl cyclase and novel paraneural functions of nitrinergic signal transduction. J Histochem Cytochem 40:1439-1456.

Steers WD, Ciambotti J, Etzel B, Erdman S, de Groat WC (1991) Alterations in afferent pathways from the urinary bladder of the rat in response to partial urethral obstruction. J Comp Neurol 310:1-10.

Tang L-H, Erdman SL, de Groat WC, Vizzard MA (1994) Increased expression of nitric oxide synthase (NOS) and growth associated protein (GAP-43) in visceral neurons after nerve injury. Soc Neurosci Abstr 20:1498.

Valtschanoff JG, Weinberg RJ, Rustioni A (1992a) NADPH diaphorase in the spinal cord of rats. J Comp Neurol 321:209-222.

Valtschanoff JG, Weinberg RJ, Rustioni A, Schmidt HHHW (1992b) Nitric oxide synthase and GABA colocalize in lamina II of rat spinal cord. Neurosci Lett 148:6-10.

Verge VMK, Zhang X, Xu X-J, Wiesenfeld-Hallin Z, Hökfelt T (1992) Marked increase in nitric oxide synthase mRNA in rat dorsal root ganglia after peripheral axotomy: in situ hybridization and functional studies. Proc Natl Acad Sci USA 89:11617-11621.

Vincent SR, Kimura H (1992) Ilistochemical mapping of nitric oxide synthase in the rat brain. Neuroscience 46:755-784.

Vizzard MA, Erdman SL, de Groat WC (1993a) The effect of rhizotomy on NADPH diaphorase staining in the lumbar spinal cord of the rat. Brain Res 607:349-353.

Vizzard MA, Erdman SL, de Groat WC (1993b) Localization of NADPH-diaphorase in bladder afferent and postganglionic efferent neurons of the rat. J Auton Nerv Sys 44:85-90.

Vizzard MA, Erdman SL, de Groat WC (1993c) Localization of NADPH-diaphorase in pelvic afferent and efferent pathways of the rat. Neurosci Lett 152:72-76.

Vizzard MA, Erdman SL, Erickson VL, Stewart RJ, Roppolo JR, de Groat WC (1994a) Localization of NADPH-diaphorase in the lumbosacral spinal cord and dorsal root ganglia of the cat. J Comp Neurol 339:62-75.

Vizzard MA, Erdman SL, Förstermann U, de Groat WC (1994b) Differential distribution of nitric oxide synthase in neural pathways to the urogenital organs (urethra, penis, urinary bladder) of the rat. Brain Res 646:279-291.

Vizzard MA, Erdman SL, Roppolo JR, Förstermann U, de Groat WC (1994c) Differential localization of neuronal nitric oxide synthase immunoreactivity and NADPH-diaphorase activity in the cat spinal cord. Cell Tissue Res 278:299-309.
Vizzard MA, Erickson VL, Card JP, Roppolo JR, de Groat WC (1994d) Transneuronal labeling of neurons in the adult rat brainstem and spinal cord after injection of pseudorabies virus into the urethra. J Comp Neurol, in press.

Wakisaka S, Kajander KC, Bennett GJ (1991) Increased neuropeptide Y (NPY)-like immunoreactivity in rat sensory neurons following peripheral axotomy. Neurosci Lett 124:200-203.

Walters ET (1994) Injury-related behavior and neuronal plasticity: an evolutionary perspective on sensitization, hyperalgesia and analgesia. Int Rev Neurobiol, in press.

Walters ET, Dulin MF, Zhang X-P, Ambron RT (1994) Hyperexcitability induced by injecting Aplysia neurons with molecules transported to the soma after axonal crush suggests a conserved mechanism for injury reactions and memory. Soc Neurosci Abstr 20:231.

Ward SM, Xue C, Shuttleworth CW, Bredt DS, Snyder SH, Sanders KM (1992) NADPH diaphorase and nitric oxide synthase colocalization in enteric neurons of canine proximal colon. Am J Physiol 263[Gastrointest Liver Physiol 26]:G277-G284.

Wiesenfeld-Hallin Z, Hao J-X, Xu X-J, Hökfelt T (1993) Nitric oxide mediates ongoing discharges in dorsal root ganglion cells after peripheral nerve injury. J Neurophysiol 70:2350-2353

Woolf CJ, Reynolds ML, Molander C, O'Brien C, Lindsay RM, Benowitz LI (1990) The growth-associated protein GAP-43 appears in dorsal root ganglion cells and in the dorsal horn of the rat spinal cord following peripheral nerve injury. Neuroscience 34:465-478.

Wu W (1992) Neuronal NADPH-diaphorase are related to survival and regeneration after severe neuronal damage. Soc Neurosci Abstr 18: 860.

Wu W (1993) Expression of nitric oxide synthase (NOS) in injured CNS neurons as shown by histochemistry NADPH-diaphorase. Exp Neurol 120:1-7.

Wu W, Li L (1993) Inhibition of nitric oxide synthase reduces motoneuron death due to spinal root avulsion. Neurosci Lett 153:121-124

Wu W, Liuzzi FJ, Schinco FP, Depto AS, Li Y, Mong JA, Dawson TM, Snyder SH (1994) Neuronal nitric oxide synthase is induced in spinal neurons by traumatic injury. Neuroscience 61:719-726

Young HM, Furness JB, Shuttleworth CWR, Bredt DS, Snyder SH (1992) Co-localization of nitric oxide synthase immunoreactivity and NADPH diaphorase staining in neurons of the guinea-pig intestine Histochemistry 92:375-378.

Yu W-H A (1994) Nitric oxide synthase in motor neurons after axotomy. J Histochem Cytochem 42:451 -457.

Zhang X, Verge V, Wiesenfeld-Hallin Z, Ju G, Bredt D, Snyder SH, Hökfelt T (1993) Nitric oxide synthase like immunoreactivity in lumbar dorsal root ganglia and spinal cord of rat and monkey and effect of peripheral axotomy. J Comp Neurol 335:563-575. 